\title{
FUNCTIONAL OUTCOME OF THE UPPER LIMB AFTER STROKE
}

\section{Blake P F, MSc Physiotherapy, University of Witwatersrand}

\section{Fritz $V U, M B B C H F C P(S A), P h D(M e d)$}

\section{SUMMARY}

Is movement regained in the hemiplegic arm after stroke translated into useful function in daily activity? As no answers could be found in the literature it was decided to investigate an effective method of assessing and measuring spontaneous use of the arm, the extent to which voluntary movement correlated with spontaneous and observed use, and aspects of neurological deficit which could adversely affect upper extremity function.

A test battery was drawn up and administered to seven stroke patients, all of whom had some recovery of the hemiplegic upper limb.

Results of the tests indicated a generally positive correlation between motor function and spontaneous and observed use, respectively, thus fulfilling the second aim of the study. The correlation also suggests that the first aim was met and that the tests were effective in what they were designed to evaluate.

Small sample size limited the conclusions which could be drawn from the results of other sub-tests. Indications were that the outcome for spontaneous use of the hemiplegic arm is poorer in patients with non-dominant hemisphere lesions. Handedness in associa tion with dominance also appears to play a part in better outcome for dominant hemisphere lesions.

In spite of the positive correlation between motor function and spontaneous use, it was felt that comprehensive evaluation of upper extremity function should be extended to include automatic use.

\section{INTRODUCTION}

Impairment of upper limb function greatly contributes to functional disability after stroke. While $50-80 \%$ of survivors will walk independently $1,2,3$, only $14 \%$ are likely to make good recovery of the upper limb 4

It is possible for stroke sufferers to manage their own self care, live independently and even return to certain types of work when no useful function of the hemiplegic limb has been regained. Nevertheless opportunities for reintegration into an active life style will be limited.

Much of the literature on the functional outcome of the upper limb after stroke concerns itself with studies which investigate recovery rates and indicators of prognosis.

There is general agreement that the earlier the return of motor function the higher the level of recoverv. the first month being the optimal period $^{5,6,7}$. Thereafter three months is considered an important recovery milestone ${ }^{7,8}$. Further recovery occurs more slowly and to a lesser extent. It may continue for as long as six to 12 months after stroke $6,7,8$.

A variety of tests and test batteries designed to measure upper limb function have also been described. However, there is no indication that functional activities performed in a test situation will be carried over into daily life.

Several authors voice this concern, for example De Souza who claims that the motor ability of the arm may not be converted into functional ability ${ }^{9}$. According to Langton-Hewer, a patient may have a considerable amount of movement in the arm but no useful function ${ }^{10}$, while Bard and Hirschberg state that voluntary motion is not identical to upper extremity function ${ }^{5}$. Nevertheless there appear to be no studies in which researchers have investigated the extent to which movement is translated into useful function in daily activity. The present study was carried out at the Johannesburg Hospital with the following aims:

- To develop an effective method of assessing and measuring spontaneous use of the arm.

- To investigate the extent to which voluntary movement correlates with automatic use.

- To identify aspects of neurological deficit which could adversely affect upper extremity function.

\section{METHOD}

A battery of tests designed to evaluate upper extremity function was administered to seven persons with residual hemiplegia following stroke. All had reached a plateau in terms of recovery and were independently ambulant. While five were independent in self care, two required minimal assistance with clothes fastenings. Their general level of ability was felt to indicate a good overall level of outcome.

The following biographical data was recorded on each patient: Age, Sex, Handedness, Side of involvement, Dates of onset and assessment, Occupational Status before and after stroke.

The tests comprising the battery were aimed at including all aspects of neurological function which, if impaired, might limit upper extremity use. They evaluated Motor function, Muscle tone, Praxis, Automatic use, Spontaneous use, Observed use, Sensation and Neuropsychological functions.

\section{MOTOR FUNCTION}

The upper extremity section of the Rivermead Motor Function assessment form was used separately as it had been independently evaluated for validity and reliability ${ }^{11}$.

The fifteen test items are hierarchically arranged according to known patterns of upper limb recovery. When a task could not be successfully completed after three attempts, the test was discontinued. Test items ranged from active protraction of the shoulder in supine at the simolest level to tving a piece of string behind the neck at the most complex.

\section{MUSCLE TONE}

Bobath describes the characteristic posture of the hemiplegic arm produced by spasticity and how spasticity interferes with movement ${ }^{12}$. Severe spasticity can prevent movement, moderate spasticity ca uses movement to be performed abnormally and with excessive effort, while mild spasticity allows movement in normal pattern but it is slower and requires more effort than normal.

To establish the presence of increased tone patients were tested for the presence of brisk tendon reflexes. Hoffman's sign and associated reactions ${ }^{13}$

The above methods of testing for increased tone do not give an indication of its distribution and intensity which is relevant to the rehabilitation therapist. Tone was therefore also assessed as the degree of resistance to passive movement at shoulder, elbow. wrist and fingers and was rated on a five point scale ranging from 
flaccidity to severe spasticity. Different methods of rating have been previously evaluated and a scale of five fixed categories was found to be the most reliable ${ }^{14}$.

\section{PRAXIS}

Geschwind defines apraxia as a disorder of execution of learned movement not accounted for bv weakness. incoordination sensory loss. incomprehension or inattention ${ }^{15}$. It was therefore deemed necessary to include assessment of apraxia in the test battery.

Five tasks commonly used in the assessment of apraxia were chosen and hierarchically graded according to the patient's ability to mime, imita te or apply an object relevant to the task, appropriately.

The activities included brushing teeth. combing hair, using a hammer, turning a kev in a lock and performing a salute.

\section{AUTOMATIC USE}

The term automatic use was chosen to indicate self-activated use of the hemiplegic upper limb at a subconscious level in everyday activities. Automatic use was further subdivided into spontaneous and observed use.

Spontaneous use was evaluated in ten bimanual activities. These were devised to involve the use of both hands. No instructions were given regarding use of the affected arm, it being hoped that residual function would spontaneously be incorporated into the activity. The extent to which the affected arm and hand participated was graded on a four point scale.

The tasks included activities such as tving shoe laces, taking toy barrels apart, transferring polvstyrene chips from one box to another and throwing and catching a large ball, Observed usewas evaluated by questionnaire. Keith states that behaviour executed on request in a structured treatment environment may not be the same as at home where action must be initiated by the individual $^{16}$. The extent to which the affected arm was used in six daily routine self care activities such as dressing, washing and grooming was noted by the patient's spouse or live-in companion over a period of time. Use was scored on a three point scale and scores were given an added weighting according to frequency of use.

\section{SENSATION}

Much is written about the influence of sensory deficits on function but how much do they really restrict function after stroke? Garland and Waters comment on a small group of stroke patients who regain good voluntary control of the hand but fail to use it ${ }^{17}$. In such cases they found sensation to be impaired

Sensation was clinically tested as follows:

Exteroception as pain and light touch

Proprioception as ioint position and vibration sense. These were compared with the unaffected side and rated as equal, slightly or very diminished, or absent. The combined sensations were evaluated by testing two point discrimination and stereog-

\section{nosis.}

\section{NEUROPSYCHOLOGICAL TESTS}

In order to identify neglect, constructional dyspraxia, disturbances of body image and body scheme, each participant was asked to do drawings both copied and from memory. In addition recognised tests of body part identification were carried out.

\section{RESULTS}

The average age of the seven patients was 59 years, six were male and one was female. All were right handed before the stroke while four were right and three were left hemiplegics.

Pre stroke occupations varied from a tiler of walls and floors, to an accountant, to a Professor of languages. Only one person continued to work at his previous job since his stroke. One had taken a different job and two had worked post stroke but were not presently working; two others had since retired and one had not worked at all.

The main object of the study was to establish whether motor. function of the affected upper limb after stroke was translated into automatic use in daily activity. Results do show a generally positive correlation between scores of motor function and spontaneoususeand motor function and observed use. They also show a positive correlation between spontaneous and observed use. However, a much larger sample would be required before these results could be generally applied.

To demonstrate the extent of the correlation between the results, the scores of the tests of motor function and automatic use were graphically plotted against each other as shown in Figures 1,2 and 3.

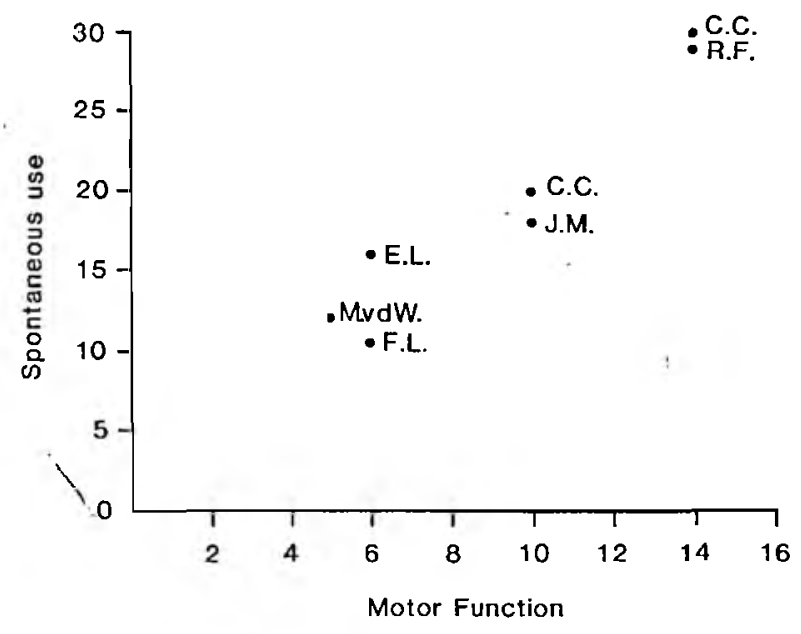

Figure 1: Correlation between motor function and spontaneous use

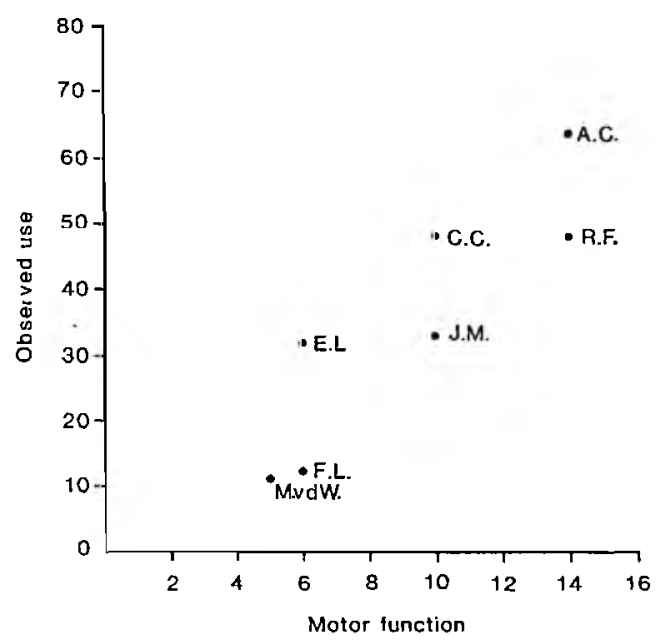

Figure 2: Correlation between motor function and observed use

As an additional method of analysis, the levels of agreement between the parameters were calculated according to the Bland Altman method ${ }^{18}$. This gives an indication of the closeness of the ability of the different parameters to measure automatic use or the extent to which they are interchangeable in doing so. The parameters were found to be in agreement within the $95 \%$ limits but had to be corrected for a varying degree of bias. 


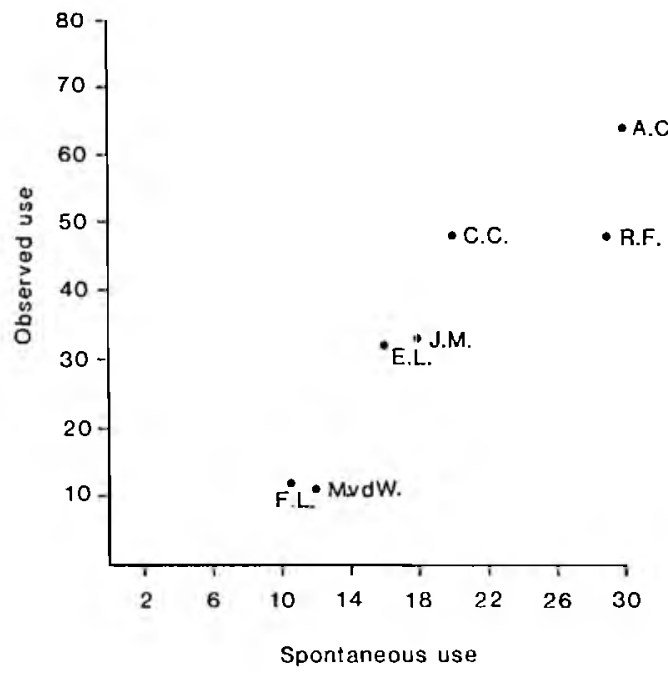

Figure 3: Correlation between spontaneous and observed use

\section{DISCUSSION}

As motor function is a prerequisite for automatic use, a positive correlation could be expected. In spite of the influence of other aspects of neurological dysfunction the correlation is sufficiently strong to indicate that the tests devised to evaluate automatic use were effective in measuring what thev were designed to measure. For wider use, inter- and intra-rater reliability would have to be established.

Although comprehensive neurological and neuropsychological evaluations were carried out on each patient, no conclusions could be drawn because of the small sample size.

Sensory loss was found to be mild and mainly distal. Further knowledge of the degree of sensory loss which could be expected to limit function would give an indication of what could be expected in terms of potential function.

With regard to evaluation of visuospatial impairments, neglect was not identified, nor were disorders of body image or body scheme. Two participants demonstrated constructional dyspraxia yet they differed widely on scores of motor function and automatic use. Hence it cannot be concluded that constructional dyspraxia has an influence on function of the affected upper limb. Both persons have been unable to work since their strokes and have additional sensorimotor signs suggestive of more extensive lesions.

\section{HANDEDNESS}

It appeared that patients with impairment of the dominant hand and arm did better than those with impairment of the non-dominant side. It could be that the stimulus to use the dominant arm predominates even when function is reduced.

\section{SIDE OF STROKE}

Side of stroke did not appear to influence test results in this study. Clinically right and left strokes present differently and require different approaches to rehabilitation; also studies on outcomes of left and right sided involvement differ in their conclusions ${ }^{19,20}$. Specific information on the functional outcome of the upper limb in left and right strokes would assist in prognosis and influence approaches to rehabilitation.

\section{CONCLUSION}

Replication of the study using a larger sample of stroke patients could yield useful information regarding neurological factors which could adversely affect upper limb function and consequent rehabilitation outcome.
This information together with other prognostic indicators such as severity of stroke, recovery rate and period post stroke is necessary for planning an effective upper limb rehabilitation programme. The study emphasises the importance of comprehensive sensorimotor evaluation which should be extended to include information on the extent to which the arm is used in daily activities. Evaluation is needed not only prior to but also at regular intervals during rehabilitation. Rehabilitation requires a team approach and findings should be shared among team members.

There is a danger of thinking that once there is some return of movement, the patient will naturally begin to use what movement there is in daily activity. This may not be the case. Maximal return of function is of such importance to the individual's qualitv of life that every effort should be invested in rehabilitating the arm to optimal outcome.

I would like to acknowledge Profressor H Reef, past Head, and Professor V U Fritz, present Head, Department of Neurology University of the Witwatersrand and Johannesburg Hospital, also Professor M Saling ex-Department of Psychology, University of the Witwatersrand who supervised the original research project.

\section{REFERENCES}

1. Hurwitz L J, Adams G F. Rehabilitation of hemiplegia: Indices of assessment and prognosis. Br Med J. 1972:1;94-98.

2. Colen B S. Considerations in prognosis after stroke. Md State Med J 1976:29-32

3. Wade D T, Wood V A, Heller A et al. Walking after stroke: Measurement and recovery over the first three months. Scand J Rehab Med 1987:19;2530 .

4. Wade D T, Langton Hewer R, Wood V A ct al. The Hemiplegic arm after stroke: Measurement and recovery. I Neurol Neurosurg Psychiatry 1983:46;521-524.

5. Bard G, Hirschberg G G. Recovery of voluntary motion in upper extremity following hemiplegia. Arch Phys Med Rehabil 1965:45;567572.

6. Parker V M, Wade D T, Langton Hewer R. Loss of arm function after stroke: Measurement, frequency and recovery. Int Rehabil Med 1986:8;69-73

7. Skilbeck C E, Wade D T, Langton Hewer R ct al. Recovery after stroke. J Neurol Neurosurg Psychiatry 1983:46;5-8.

8. Wade D T, Langton Hewer R, Wood V A et al. The Hemiplegic arm after stroke: Measurement and recovery. I Neurol Neurosurg Psychiatry 1983:46;521-524.

9. De Souza L H, Langton Hewer R, Miller S. Assessment of recovery of arm control in hemiplegic stroke patients. I. Arm Function Tests. Int Rehab Med 1980:2;3-9.

10. Langton Hewer R. How does arm movement recover? Practitioner 1979:223;800-803.

11. Lincoln N, Leadbitter D. Assessment of Motor Function in Stroke Patients. Physiotherapy 1979:65(2);48-51.

12. Bobath B. Adult Hemiplegia: Evaluation and Treatment 2 nd ed. London: William Heineman 1978:26-27.

13. De Jong $\mathrm{R} N$. The Neurologic Examination. 4th ed Hagerstown:Harper Row 1979.

14. Blake P F. Spasticity: Can it be Measured? Proceedings IXth International Congress of the World Confederation for Physical Therapy. Part II, Stockholm: AB Grafiska Gruppen, 1982.

15. Geschwind N. The Apraxias: Neural Mechanisms of Disorders of Learned Movement. AM Sc 1975:63;188-195.

16. Keith R A. Functional assessment measures in medical rehabilitation: Current status. Arch Phys Med Rehabil 1984:65;74-78.

17. Garland D E, Water R I. Orthopaedic evaluation in hemiplegics stroke. In Bowker JK (Ed). The Orthopaedic Clinics of North America. Philadelphia: WB Saunders Company, 1978:(9)291-303.

18. Bland J M, Altman D G. Statistical methods for assessing agreement between two methods of clinical measurement. The Lancet 1986:1;307. 310 .

19. Denes G, Semenza C, Eudes S et al.-Unilateral Spatial neglect and recovery from hemiplegia. Brain 1982:105;543-552.

20. Mills V M, Digenia M. Functional differences in patients with left or right cerebrovascular accidents. Phys Ther 1983:63(4);481-485. 